\title{
Synthesis of conduritols and related compounds
}

\author{
Metin BALCI \\ Atatürk University, Department of Chemistry, Faculty of Science, Erzurum, TURKEY
}

\begin{abstract}
New and stereospecific syntheses for all conduritol isomers have been developed starting from appropriate 1.3-cyclohexadiene derivatives. Oxygen functionalities were introduced by photooxygenation. Application of the ene-reaction of singlet oxygen to 1.4-cyclohexadiene and its derivatives afforded diene system which can be easily trapped by second mol of singlet oxygen to give 49 and 50 . Thiourea reduction of the peroxide linkages followed by oxidation gave the corresponding pentol derivatives. Furthermore, reaction of unsaturated endoperoxides with 1.2.4.5tetraazine derivatives \$9-63 afforded new bicyclic endoperoxides with unusual structures.
\end{abstract}

\section{Introduction}

Conduritols ${ }^{1}$ are 1,2,3,4-cyclohexenetetrol isomers and interesting inhibitors for glycosidases ${ }^{2}$. A number of conduritol derivatives have been found to possess antifeedant ${ }^{3}$, antibiotic, antileukemic, and growth-regulating ${ }^{1}$ activity. There are also many plant metabolites like crotepoxide, senepoxide, pipoxide, (Scheme 1) which have four oxygen bonded substituents on a cyclohexene-ring, exhibiting interesting biological properties including tumour-inhibitory, antileukaemic, and antibiotic activities. Therefore, the synthesis of these compounds gain interest. In this paper, we describe a new synthetic methodology leading to the synthesis of various conduritols and related compounds.

Before synthesis of conduritol derivatives we have developed a synthetic methodology for tetrahydroxy-cyclohexan derivatives. Therefore, we want to discuss at first the synthesis of some cyclitols derived from cyclohexane.<smiles>OC1C=CC(O)C(O)C1O</smiles>

Conduritol-A<smiles>OC1C=CC(O)[C@H](O)C1O</smiles><smiles>NC1C=C(CO)C(O)C(O)C1O</smiles>

Valienamine<smiles>CC(=O)OC1C2O[C@@H]1C=C[C@H]2OC(C)=O</smiles>

Senepoxide<smiles>O=C(OC[C@@]12OC1C=C[C@H](Oc1ccccc1)C2O)Oc1ccccc1</smiles>

Pipoxide<smiles>CC(=O)OC1CC23CC2C2OC2C2OC2C13OC(=O)c1ccccc1</smiles>

Seneol

\section{Cyclitols: Cyclohexanetetrols}

Theoretically six cyclohexanetetrols diastereoisomers are possible (Scheme 2). Some of these occur in the nature ${ }^{4}$. These compounds have been synthesized either by reduction of the corresponding conduritols ${ }^{5}$ or by direct hydroxylation of 1,3 -cyclohexadiene ${ }^{6}$ (Scheme 3 ). Direct hydroxylation of the appropriate cyclic dienes is not a suitable method for the synthesis of the corresponding tetrols. 
Our synthetic sequence is based on introduction of the two oxygen functionality's by photooxygenation of 1,3-cyclohexadiene. The other oxygen functionality's are introduced through the classical peracid epoxidation reaction 7 . Oxidation of the endoperoxide 8 obtained by photooxygenation ${ }^{8}$ of cyclohexadiene, with $m$-chloroperbenzoic acid gives two isomeric epoxy endoperoxides in a 55:45 ratio. These isomers were separated by column chromatography on silica gel. The ${ }^{1}$ H-NMR spectra of these epoxy endoperoxides are consistent with the symmetry of their structures. However we were not able to distinguish between the two isomers 3 and 4 on the basis of the spectral data. The configurational assignment of syn and anti to the isomeric epoxy endoperoxides is easily made by chemical means. We synthesized the anti isomer 4 by an independent route from oxepine-benzene oxide 6 as shown below.

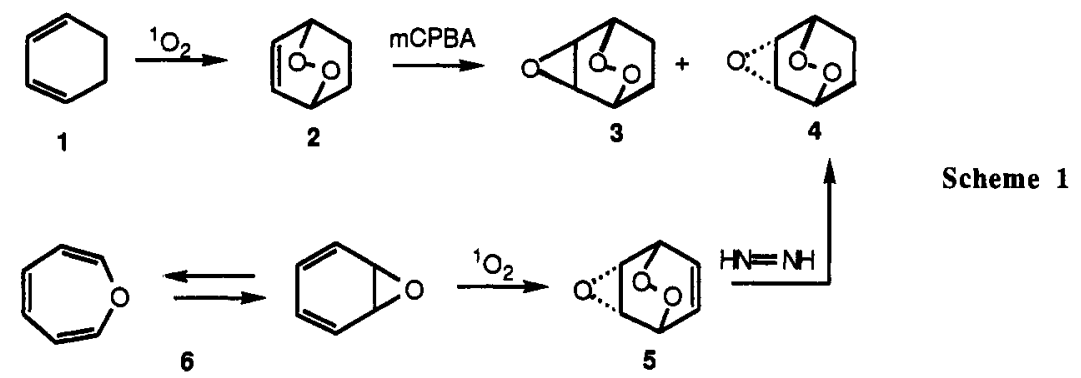

Foster and Berchtold ${ }^{9}$ reported that reaction of oxepine-benzene oxide with singlet oxygen afforded the unsaturated anti epoxy endoperoxide 5. Reduction of the double bond in 5 with diimide occurs without reduction of the peroxide bond to give anti epoxy endoperoxide 4 quantitatively, which was identical with the major product obtained by photooxygenation of 1.3-cyclohexadiene followed by epoxidation of the formed bicyclic endoperoxide 2 (Scheme 1).
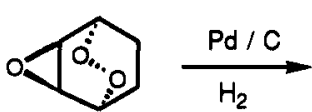

4

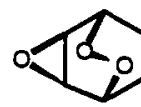

3

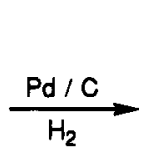

$$
\text { (1) }
$$<smiles>CC1CC[C@@H](O)C2OC12</smiles><smiles>CC1CCC(O)C2OC12</smiles>

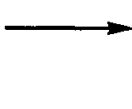
Catalytic hydrogenation of 3 and 4 gave epoxy diols 7 and 9 . Since only the oxygen-oxygen bond
breaks in this reaction 8 , the configuration at all four carbon atoms must be the same as in the starting
material. For further characterization, 7 and 9 were converted to the corresponding diacetates 8 and 10 material. For further characterizatic

In the trans epoxide ring opening by addition of water in a classic $S_{N} 2$ mechanism, both epoxides 7 and 9 gave the cyclitol 110. (Scheme 2).

After completing the synthesis of $\mathbf{1 1}$ we were interested in the synthesis of the anti-symmetrical diol 14 which opens entry to tetrols 15 and 16. Therefore we studied the $\mathrm{NEt}_{3}$-catalyzed rearrangement of 3 and 4. Base-catalyzed reaction of bicyclic endoperoxides results generally in the formation of hydroxyketones. Treatment of 3 and 4 with triethylamine led within a few hours to the expected epoxy ketols 12 and 13 in high yields. While catalytic hydrogenation of 3 and 4 affords only symmetrical epoxy diol 7 and 9, reduction of 12 and 13 with $\mathrm{NaBH}_{4}$ in methanol provides a mixture of diols in both cases 
(7/14 and 9/14). Newly formed epoxy diol 14 has been separated by column chromatography and identified by spectroscopic data.

Ring opening of 14 from which a pair of diastereoisomers is expected, with acidified water produced a mixture of 15 and 16 (Scheme 3). Spectral data of these cyclohexanetetrols were completely in agreement with those reported in the literature ${ }^{7}$.

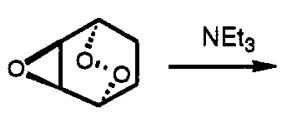

4

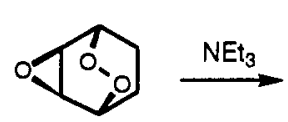

3

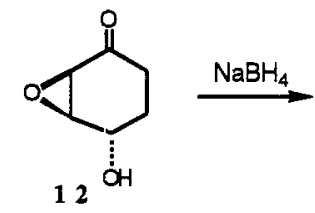<smiles>O=C1CC[C@@H](O)[C@H]2O[C@H]12</smiles>

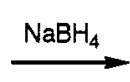<smiles>OC1C2OC2[C@H](O)CC[C@@H]1O</smiles><smiles>OC1CCC(O)C2OC12</smiles>

$+$<smiles>O[C@H]1CC[C@@H](O)[C@H]2O[C@H]12</smiles>

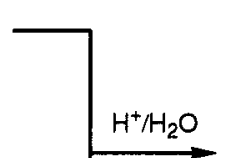<smiles>OC1CC[C@@H](O)[C@H](O)[C@H]1O</smiles>
15<smiles>OC1CC[C@@H](O)[C@H](O)C1O</smiles>

16

Scheme 3

\section{CONDURITOLS}

Conduritols are 1,2,3,4-cyclohexenetetrol isomers. Theoretically, six conduritol diastereoisomers are possible. To avoid ambiguity, the diastereoisomers have been called with letters $A, B, C, D, E, F^{1}$. In the nature the occurrence of only two conduritols, namely Conduritol-A and Conduritol-B has been established.<smiles>OC1C=CC(O)C(O)C1O</smiles><smiles>OC1C=CC(O)C(O)C1O</smiles>

CONDURITOL-A<smiles>OC1C=C[C@@H](O)[C@H](O)[C@H]1O</smiles>

oH<smiles>OC1C=CC(O)C(O)C1O</smiles>

CONDURITOL-D<smiles>OC1C=C[C@@H](O)[C@H](O)[C@H]1O</smiles><smiles>O[C@H]1C=C[C@@H](O)[C@H](O)[C@H]1O</smiles>

CONDURITOL-E CONDURITOL-F

Conduritol-A :In 1908 Kübler $^{11}$ isolated from the bark of the vine Marsdenia Condurango the first known cyclohexenetetrol which was named as Conduritol-A. The first succesfull and non-stereospecific synthesis of conduritol-A was carried out by Nakajima et al. ${ }^{12}$.<smiles>CC1(C)OC2C=CC=CC2O1</smiles>

17<smiles>CC[18OH]</smiles><smiles>CC1(C)OC2C3C=CC(O3)C2O1</smiles>

18
Thiourea<smiles>C1CCCC1</smiles>

19 aे

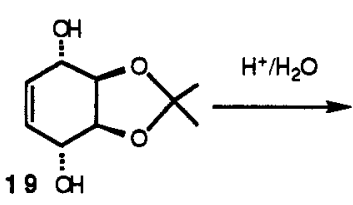

Scheme 4

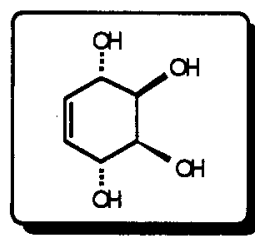

20 CONDURITOL-A 
Our synthetic strategy is based on the introduction of two oxygen functionalities at the $\mathrm{C}_{2}$ and $\mathrm{C}_{3}$ positions by $\mathrm{KMnO}_{4}$-oxidation and the other two oxygen functionalities at the $\mathrm{C}_{1}$ and $\mathrm{C}_{4}$ positions by photooxygenation 13 . The key compound 17 in the synthesis of conduritol-A was synthesized as described on Scheme 4. Photooxygenation of 17 at room temperature afforded 18 in a yield of $95 \%$. The exact configuration of $\mathbf{1 8}$ was determined at the final step.

Selective reduction of the peroxide linkage was performed with thiourea under very mild condition to give 19 in $80 \%$. Since only the oxygen-oxygen bond breaks in this reaction, it preserves the configuration. Deketalisation of 19 was carried out in acidified methanol solution in quantitative yield. The spectroscopic properties of 20 compared well with those of the previously reported conduritol- $\mathrm{A}^{14} \mathbf{2 0}$.

Conduritol-F and Conduritol-B: In 1962, Plouvier ${ }^{15}$ discovered a new optically active cyclitolisomer from Crysanthemum Leucanthemitol which was isomer with conduritol-A and he named this new conduritol isomer as L-Leucanthemitol (Conduritol-F). Conduritol-F can be detected at least in traces in almost green plants. We have developed a new and stereo specific synthesis for conduritol-F by two different approaches 16

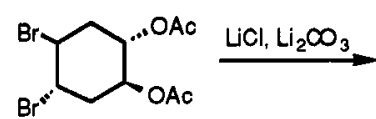

21

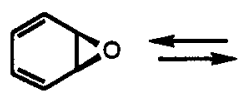

6

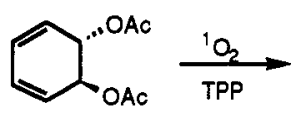

22<smiles>CC(=O)OC1OC2C=CC1[C@H](O)[C@H]2OC(C)=O</smiles>

23
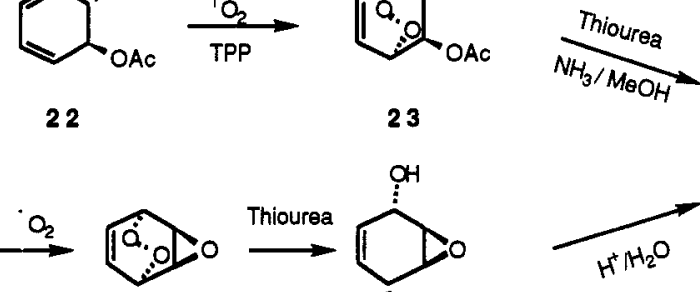

5<smiles>CC1C=C(O)C2OC2C1O</smiles>

OH 25

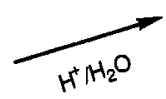

24

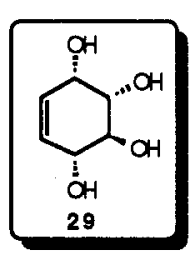

4 CONDURITOL-F

Scheme 5

For the first approach we used the known trans-benzene diacetate $22^{17}$ (Scheme 5). Photooxygenation of trans-benzene diacetate afforded the endoperoxide 23 in $56 \%$ yield. At this step we introduced all possible oxygen functionalities in correct configuration as desired in conduritol-F. Selective reduction of the peroxide linkage with thiourea followed by deacetylation of 23 was carried out with ammonia in methanol to give conduritol-F 24 which was identical with those reported in the literature.

In the second approach, we started from the endoperoxide 5 which has been synthesized by photooxygenation of the system benzene oxide-oxepine. Reduction of the peroxide-linkage in 5 with thiourea and acid-catalyzed ring opening reaction of 25 afforded conduritol-F 24 which was identical with the compound obtained from the first sequence.

In another reaction we converted epoxy diol 25 into the corresponding epoxy diacetate 26. Epoxy diacetate was submitted to acid-iatalyzed ring-opening reaction in acetic anhydride. Analysis of the reaction<smiles></smiles>

26

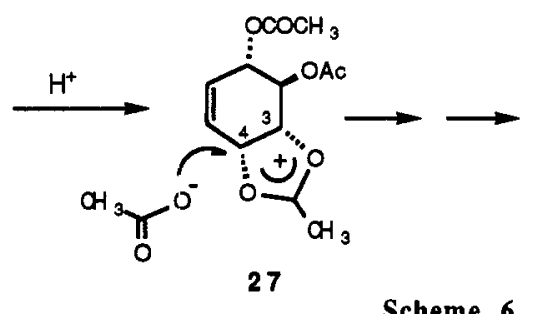

Scheme 6

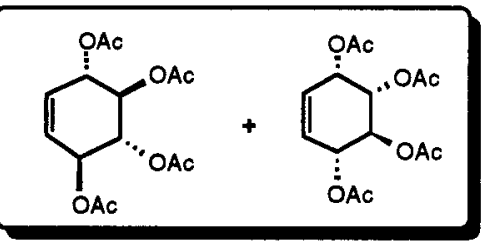

28 CONDURITOL-B 24 CONDURITOL-F 
mixture has revealed that the product was consisting from two isomers, conduritol-F 24 and conduritol B 28 in a ratio of $2: 1$. The formation of conduritol-B has a likely explanation on the basis of the involving of the neighboring acetoxy group on the course of the epoxide ring-opening as shown on scheme 6.

Conduritol-C and Conduritol-E: The first synthesis of conduritol-C was carried out by McCasland and Reeves ${ }^{18}$ from epiinositol. Yurev and Zefirov19a have described a short synthetic way to conduritol-C starting from cycloaddition product of furan and ethylene carbonate. In this paper we describe two different synthetic ways leading to the synthesis of conduritol-C and conduritol- $\mathrm{E}^{19 \mathrm{~b}}$.

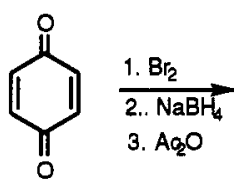

29<smiles></smiles>

30<smiles>OC1CCC(O)[C@@H](Br)[C@H]1Br</smiles>

34<smiles>O[C@@H]1[C@@H]2O[C@H]2[C@@H](O)[C@@H](Br)[C@@H]1Br</smiles>

35<smiles>CC(=O)OC1C(O)C(O)C(Br)C(OC(C)=O)C1Br</smiles>

31<smiles>CC(C)C1(Br)C(Br)C(O)[C@@H](O)[C@H](O)C1O</smiles>

36

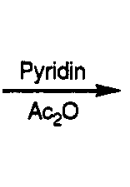

$\underset{\mathrm{ZnNMMO}}{\stackrel{\mathrm{DNP} / \mathrm{H}^{+}}{\longrightarrow}}$ 6<smiles>CC(=O)OC1C(Br)C(Br)C(OC(C)=O)C(OC(C)=O)C1OC(C)=O</smiles>

32

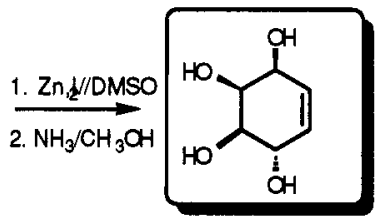

33 CONDURITOL.C

Scheme 7

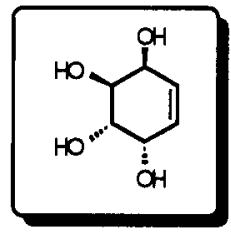

38 CONDURITOL. E

cis-Hydroxylation of the known compound $\mathbf{3 0}^{20}$ led to $\mathbf{3 1}$ as the sole isomer. The tetraacetate $\mathbf{3 2}$ gave upon reaction with zinc-DMSO the unsaturated tetraacetate from which the free tetrol conduritol-C 33 was obtained by ammonolysis (Scheme 7).

The first synthesis of conduritol-E was described by Nakajima et al. 12 in 1957 which was not stereospecific and not useful. A stereospecific synthesis for conduritol-E was described by Angyal and Gilham 21 and later again by Nakajima 22 . We used by our synthesis 34 , whose oxidation with $\mathrm{m}$ chloroperbenzoic acid (m-CPBA) gave the epoxy compound 35. In the trans epoxide ring-opening by addition of water, in a classic substitution mechanism, $\mathbf{3 5}$ should give two different opening products. However, we obtained only $\mathbf{3 6}$ which is the precursor of the conduritol-E. For further reaction we converted the tetrol into the readily obtained di-O-isopropylidene derivative 37 . This cyclic ketal reacted smoothly with zinc-DMSO and gave conduritol-E 38.

Aminoconduritols; Conduramine F4 : Aminoconduritols show also interesting inhibitor activity for some glycosidases. Synthesis of some amino conduritols has been reviewed 23 . The synthetic methodology developed by us opened up entry to the synthesis of various aminocyclitols. We describe the synthesis of conduramin $\mathrm{F}_{4} \mathbf{4 1}$ which has the same configuration as conduritol-F.<smiles>CC1(C)O[C@H]2OC3C=CC(O3)[C@H]2O1</smiles>

18

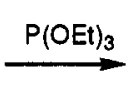

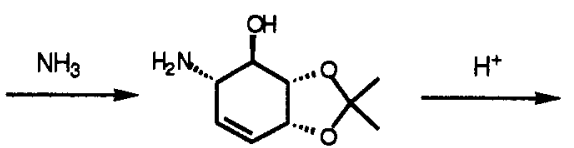

40

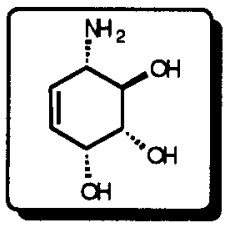

41 CONDURAMIN F $_{4}$

Scheme 8

The key compound was the endoperoxide 18. Triethylphosphite reduction of the endoperoxide 18 was resulted in the formation of epoxy ketal 39 with definitive configuration. Acidic hydrolysis of this 
compound gave conduritol-F as the sole product. Nucleophilic substitution with $\mathrm{NH}_{3}$ followed by acidic hydrolysis afforded conduramin $\mathrm{F}_{4} \mathbf{4 1}$ as the sole product (Scheme 8).

\section{Conduritol Analogues}

In this section we want to discuss the synthesis of compounds derived from bicyclooctatriene which have similar structures to conduritols. Because of biological activity of the conduritol and aminoconduritol derivatives, we undertook the synthesis of the isomeric tetrols starting from bicyclooctatriene in order to see whether this kind of molecules show biological activity or not. Bicyclic endoperoxide $43^{24}$ synthesized by photooxygenation of the corresponding diene (Scheme 9) was submitted to thiourea reduction. The formed diol was converted to the corresponding diacetate for further characterization. Epoxidation of 44 resulted in the formation of only one isomer 45 whose exact configuration could not be determined. $\mathrm{Zn}$-elimination followed by acidic hydrolysis gave the unsaturated cyclitol $\mathbf{4 8}$ in high yield. The orientation of the four hydroxyl groups in $\mathbf{4 8}$ is completely in agreement with conduritol-F. ${ }^{1} \mathrm{H}-$ and ${ }^{13} \mathrm{C}-\mathrm{NMR}$ spectral studies indicates also the asymmetric structure.

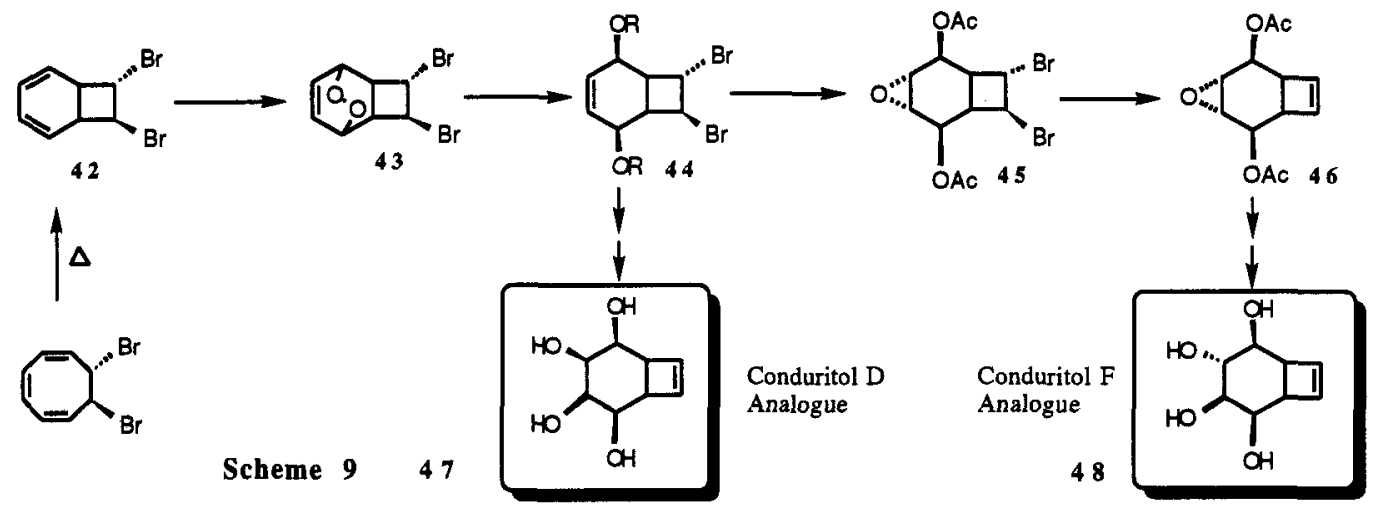

After successful synthesis of $\mathbf{4 8}$ we turned our attention to the synthesis of other conduritol analogues. Dibromo diacetate $\mathbf{4 4}$ served as the starting material. cis-Hydroxylation was carried out with $\mathrm{KMnO}_{4}$. The formed compound was characterized as the tetraacetate. The tetraacetate gave upon reaction with zinc-acetic acid unsaturated tetra acetate from which the free tetrol $\mathbf{4 7}$ was obtained by ammonolysis (Scheme 9). The exact configuration and the symmetry in the molecule was determined by ${ }^{1} \mathrm{H}-$ and ${ }^{13} \mathrm{C}$ NMR spectral measurements. Finally, the X-ray analysis of the corresponding tetraacetate indicated to our surprise that the formed compound has conduritol-D structure not the expected conduritol-A.

\section{Cyclohexanepentols: Quercitols}

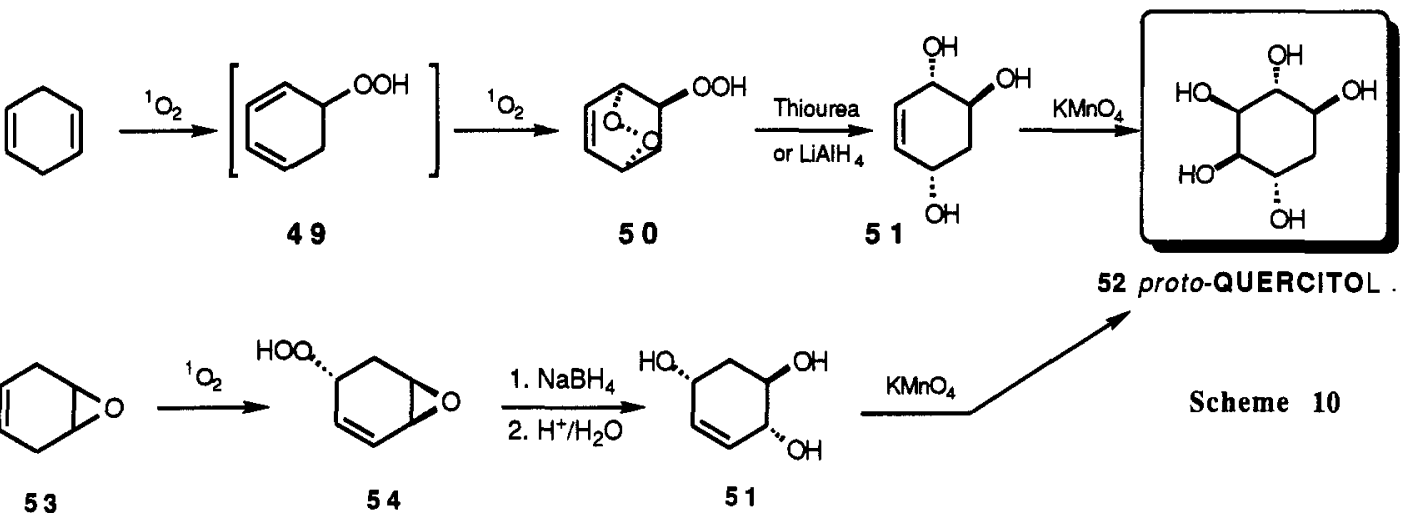


The first known cyclohexanepentol was a dextrorotatory cyclitol obtained from the acorns of Quercus species (oaks) hence the name $(+)$ quercitol. The structure and configuration were elucidated 26 . The synthesis of quercitol is reported in the literature. We describe a short, efficient and stereospecific synthesis for racemic quercitol (Scheme 10). Tetraphenylporphine-sensitized photooxygenation of 1,4cyclohexadiene gave the endoperoxide 50. We assume that singlet oxygen undergoes an ene-reaction to give 49 . The conjugated diene unit in $\mathbf{4 9}$ can be easily trapped by singlet oxygen 27 . Reduction of the peroxide linkage in 50 with thiourea followed by $\mathrm{KMnO}_{4}$ oxidation provided racemic proto-quercitol $\mathbf{5 2}$ in high yield. A second route ${ }^{28}$ for the synthesis of $\mathbf{5 2}$ based on photooxygenation of $\mathbf{5 3}$ to give $\mathbf{5 4}$. Reduction of the peroxide with sodium borhydride and followed by trans opening of the epoxide ring resulted in the formation of the key compound $\mathbf{5 1}$.<smiles>CC1(C)OC2CC=CCC2O1</smiles>

55<smiles>CC1(C)OC2C=C[C@@H](OO)CC2O1</smiles>

56

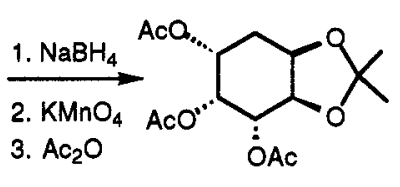

57

Scheme 11

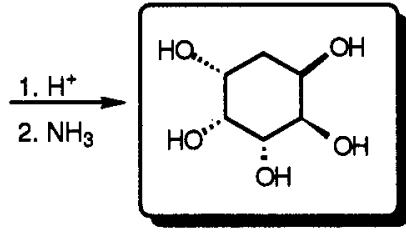

58 talO-QUERCITOL.

Application of the ene reaction of singlet oxygen to ketal 55 formed the hydroperoxide 56 whose configuration was established by $\mathrm{NOE}$-measurements ${ }^{29}$. $\mathrm{KMnO}_{4}$ oxidation of the double bond in 56 formed the correct configuration of talo-quercitol 58. Suitable hydrolysis of the acetates and ketal ring gave 58 .

\section{Miscellaneous}<smiles>Pc1nnc(P)c2c1C1CCC2O1</smiles>

59<smiles>Pc1nnc(P)c2c1C1CCC2O1</smiles>

60<smiles>[R]c1nnc([R])c2c1C1OC1C1OC(C)(C)OC21</smiles>

61<smiles>[R]c1nnc([R])c2c1C1CCCC2O1</smiles>

62<smiles>[R]c1nnc([R])c2c1CC1CCC2OO1</smiles>

$63 \mathrm{R}=\mathrm{COOCH}$.

More recently, we succeeded in the synthesis of some interesting bicyclic endoperoxides $\mathbf{5 9 - 6 3 ^ { 3 0 }}$ which contain heteroaromatic ring. The addition of 1.2.4.5-tetraazin derivatives to the appropriate unsaturated bicyclic endoperoxides followed by nitrogen extrusion gave dihydro derivative 65 . Aromatization proceeded smoothly where the peroxide linkage was remained. Chemistry and application of these compounds to the synthesis of some natural products are under investigation.

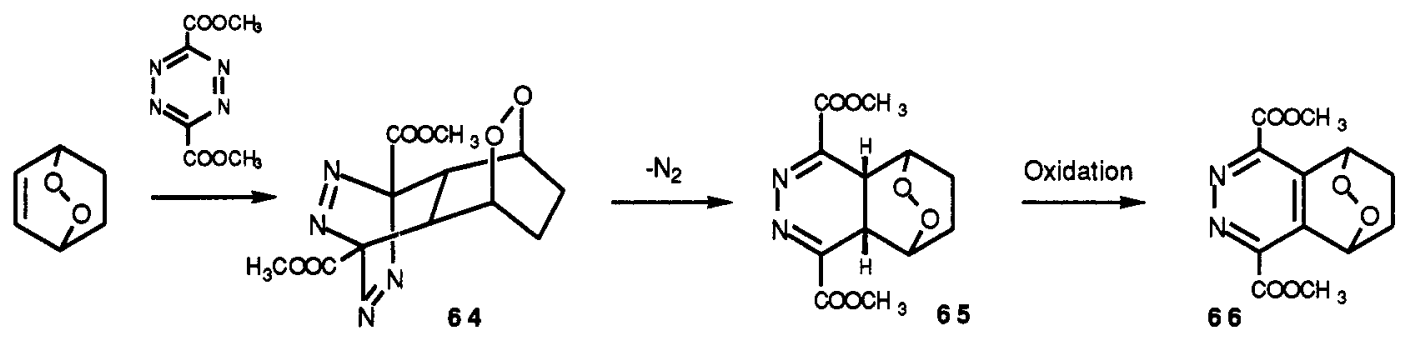

Scheme 12 
Acknowledgement: The author are indebted to the Atatürk University (Grant No. AFP 1989/31, 1991/6) and Department of Chemistry and Scientific and Technical Research Council of Turkey (DPT-TBAG-6, TBAG1063, ) for providing the necessary funds to enable our recent exploration into the chemistry of cyclitols. Furthermore, I am gratefull to my students whose names are given in the references.

\section{References}

1) For a recent review of conduritols see: M. Balc1, Y. Sütbeyaz, H. Seçen, Tetrahedron, 46, 3715 (1990) and references cited therein.

2) a) S. Atsumi, K. Umezawa, H. linuma, H. Naganawa, H. Nakamura, Y. Iitaka, T. Takeuchi, J. Antibiot. 43, 49 (1989). b) G. Legler, E. Bause, Carbohydr. Res. 28, 45 (1973). c) G. Legler, W. Lotz,.; Z. Physiol. Chem. 354, 243 (1973).

3) N. Chida, K. Yamada, S. Ogava, S. J. Chem Soc. Chem. Commun. 588 (1991).

4) Z. Zeying, Z. Mingzhe, Jiegou Huaxue, J. Struct. Chem. 6, 128 (1987).

5) G. E. McCasland, E.C. Horswill,. J. Am. Chem. Soc. 75, 4020 (1953).

6) a) H. Z. Sable, K.A. Powel, H. Katchian, C. B. Niewoehner, S. B. Kadlec, Tetrahedron, 26, 1509 (1970). b) J. A. Franks, B. Tolbert, R. Steyn, H. Z. Sable, J. Org. Chem. 30, 1440 (1995). c) R. Steyn, H. Z. Sable, H.Z Tetrahedron, 25, 3579 (1969).

7) N. Akbulut,M. Balc1, J. Org. Chem. 53, 3338 (1988).

8) M. Balc1, Chem. Rev. 81, 91 (1981).

9) C. Foster, G. A. Berchtold, J. Org. Chem. 40, 3743 (1975).

10) T. Posternak, H. Friedli, Helv. Chim. Acta. 36, 251 (1953)

11) a) K. Kubler, Arch. Pharm. Ber. Stsch. Pharm. 246, 620 (1908). b) see also: P. E. Manni, J. E. Sinsheimer, J. Pharm. Sci. 54, 1541 (1965).

12) a) M. Nakajima,I. Tomida, S. Takei, Chem. Ber, 90, 246 (1957). b) S. Knapp, R. M. Omaf, K. E. Rodriques, J. Am. Chem. Soc. 105, 5494 (1983).

13) Y. Sütbeyaz, H. Seçen, M. Balc1, M. J. Chem. Soc. Chem. Commun. 1330 (1988)

14) R. J. Abraham, H. Gottschalck, H. Paulsen, W. A. Thomas, J. Chem. Soc. 16268 (1965)

15) V. Plouvier, C.r. hebdomad. Sc'Acad. Sci. Paris, 360 (1962).

16) H. Seçen, Y. Sütbeyaz, M. Balc1, Tetrahedron Lett. 31, 1323 (1990).

17) M. R. Demuth, P. E. Garret, J. D. White, J. Am. Chem. Soc. 98, 634 (1976).

18) G. E. McCasland, J. M. Reeves, J. Am. Chem. Soc. 77, 1812 (1955).

19) a) Y. K. Yurev, K. Zefirov, Zh. Obshchei Khim, 31, 685 (1961). b) H. Seçen, A. Maraş, Y. Sütbeyaz,M. Balcı, Synth. Commun. 22, 2613 (1992).

20) H. J. Altenbach, H. Stegelmeier,E. Vogel, E. Tetrahedron Lett. 3333 (1978).

21) S. J. Angyal, P. T. Gilham, J. Chem. Soc. 375 1955).

22) M. Nakajima, I. Tomida, S. Takei, Chem. Ber. 92, 163 (1959)

23) T. Posternak, The Cyclitols Hermann, Paris, (1965).

24) a) M. Oda, Y. Kayama, Y. Kitahara, Y. Tetrahedron Lett. 2019 (1974).

25) a) A. C. Cope, N. A. Nelson, D. S. Smith, J. Am. Chem. Soc. 76, 1100 (1954). b) R. M. Carlson, R. K. Hill, Org. Synth. 50, 24 (1970).

26) G. E. McCasland,M. O. Naumann, L. J. Durham, J. Org. Chem. 33, 4220 (1968).

27) a) H. Seçen, E. Salamc1, Y. Sütbeyaz, Synlett, 609 (1993).

b) For similar reaction see: I. Saito, K. Tamoto, A. Katsumura, Chem. Lett. 127 (1978).

28) Gültekin, S.; Salamcı, E.; Sütbeyaz, Y.; Balcı, M. unpublished results.

29) A. Maras, M. Balcı, unpublished results.

30) N. Saraçoglu, A. Menzek, M. Balcı, unpublished results. 